\title{
Ergonomics work analysis applied to dentistry - a Brazilian case study
}

\author{
Custódio RARa*, Silva CESb and Brandão JGTa \\ ${ }^{a}$ Deparment of Mechanical, State University of São Paulo, Av. Professor Ariberto Pereira da Cunha, 333 \\ Guaratinguetá-SP, Brazil \\ ${ }^{b}$ Deparment of Production Engineering, Federal University of Itajubá, Av. BPS, 1303, Itajubá-MG, Brazil
}

\begin{abstract}
This paper presents the Ergonomic Work Analysis method in a Brazilian Dentist's office. Through the study, the constraints and the strategies in avoiding them were identified. It was found that dentists hardly use the position most indicated by the International Organization for Standardization (ISO) and the Federation Dentaire Internacionale (FDI) for both the patient and the dentist, which is respectively supine and 9 o'clock, due to the limited space and layout. Five types of treatments performed by the professional have been studied. The frequency and duration of actions in these treatments were accounted for and the standard positions adopted were identified. The AET was found to be a very suitable method to grasp the dentist's activity and build a point of view of the profession, which is characterized as: stressful, perfectionist and restrictive. Time management is presented as an important strategy to control the tension arising from performing the treatments.
\end{abstract}

Keywords: dentist, EWA, MSDs, ergonomics, dentistry

\section{Introduction}

This article presents the ergonomic analysis performed in a Brazilian dentist's office. It appears that there is a low frequency of studies that address this professional activity [16]. This category experiences a decrease in the productivity of services and the need to acquire strategies to adapt to the job due to symptoms that develop because of work-related muscoskeletal disorders (MSDs), especially in the neck, shoulders and spine $[2,11,15,18]$. This is evident by early retirement observed among dentists [4]. Therefore, the intention is to build a view of the dentist's activity by applying the Ergonomic Work Analysis methodology [7], and through it, identify the restrictions as well as the strategies used to avoid them.

\section{Methods}

The research is qualitative and the method chosen was the AET. For this case study, the selected subject was a 46 year-old, right-handed female dentist, who has been practicing for 22 years without an assistant in a general practice as a self-employed professional.

To analyze the case through the AET, several instruments that facilitated the concerning activity were employed. These instruments were: open notes, document analysis, systematic observations, semi-structured interviews, verbalizations and the equipment used to record the data (tape, camera, goniometer).

\section{Results and discussion}

\subsection{Analysis of demand}

The initial demand was made on the first visit where the open observations began. Below is the explicit demand of the dentist.

"Given the academic notion of ergonomics, with the heterogeneous group of patients with labyrinthitis, the elderly, pregnant women, I cannot put the Threndelemburg and 9 o'clock positions into practice. I acquired the insecurity of indirect vision. The anatomy of teeth is very similar and can decrease the accuracy of the work." 
The reformulation of the demand is made from knowledge of the elements at play in this issue initially placed. We identified the following premise:

\subsubsection{Ergonomics}

The principal is clear that the provider makes little use of the most suitable position according to the International Organization for Standardization (ISO) and the Federation Dentaire Internacionale (FDI) for both the patient and the dentist, which is respectively, supine and 9 o'clock (Figure 1). It recommends not using indirect vision with the help of a clinical mirror indicating that the dentist must perform many inclinations and rotations of their head and torso to have direct vision. The latter in turn increases the activity of neck muscles [20]. She, the dentist, reveals that she has a notion of ergonomics at work, but does not follow them. Thus, the professional adapts to the position and the needs of the patient in detriment to her own comfort to achieve a satisfactory result. She said that she has had right-sided Epicondylitis (Tennis Elbow) which resulted in her taking a 3-month leave and currently presents left-sided Epicondylitis, coccyx pain, and frequent headaches. Research conducted with 284 dentists showed a presence rate of $58 \%$ of headaches in the population studied [14]. Other complaints stem from meeting with a high incidence of MSDs in the neck, shoulders, upper extremities and lower back, shown in several studies performed on dentists $[2,12,15,18]$.

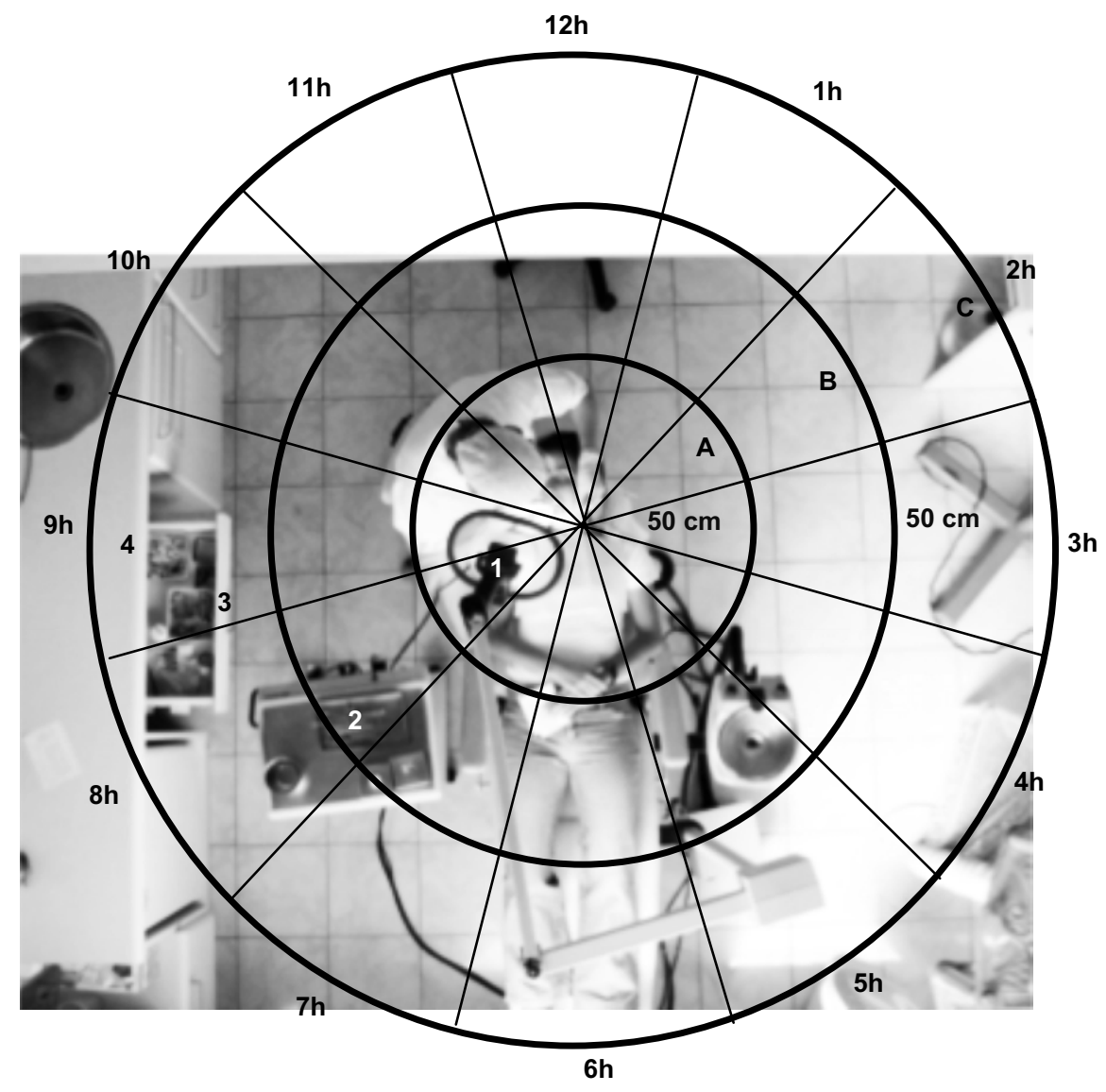

Figure 1

Schematic ISO/FDI graph of a dentist's workstation.

Legend: (1) spotlight; (2) instruments; (3) cabinet; (4) counter 


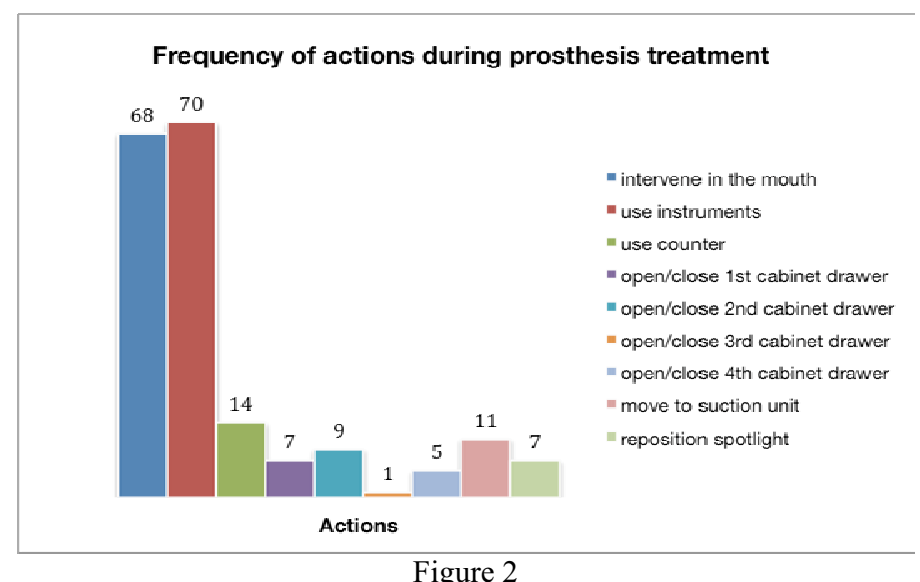

Frequency of actions

\subsubsection{Well-being of the patient}

This demand also points to a concern with the comfort of the patient which throughout the observations made, was confirmed as a strong premise. The relationship with the patient is one of the stresses of dental work [19]. Through the effort to satisfy the needs of the patient, the dentist has neglected the promotion of their own health and professional practices [21].

\subsubsection{Success of treatment}

Treatment success is linked to the accuracy that the dentist has to have during the procedure. She reports that when she does sculpting work, her entire body gets tense. It is true that there is an increase in spinal muscular activity when the professional is subjected to physical stress [13]. The success is also linked to the welfare of the patient who collaborates with the treatment remaining calmer, confident and secure [19].

From these premises it was possible to reformulate the initial demand and conduct research to identify the restrictions of this job that in turn makes the professional not follow the basic rules of dental ergonomics and continue to be exposed to the risks of developing musculoskeletal pain. In addition, the adopted strategies to address these constraints were sought to be identified. The choice of this path is justified due to the fact that the professional presents osteomuscular pain.

\subsection{Activity analysis}

A systematic observation was made in the analysis of the activity of the procedures performed in five types of treatments that the dentist offers: light cured restoration, amalgam restoration, dental prosthesis, cosmetic and preventative dentistry.

A flowchart was made for each type of treatment with the steps required for the dentist to follow for execution. Since it is the AET approach, it was considered that for each step a task was to be fulfilled, i.e., the steps required to be developed in a particular order to perform the dental treatment and could not be altered or changed for convenience purposes. After observing all the treatments, the first cut in the activity was made to proceed with the same analysis. Dental prosthesis treatments and light cured restorations were chosen for having a great deal of handling of materials, being of a higher cost and are performed more frequently than other. Therefore the concern with the result and client satisfaction is greater.

The frequency and timing of actions in these two types of treatments were recorded and analyzed (Figure 2).

A large intraoral intervention can be seen in the graph, 68 times and great use of the equipment, 70 times. For these actions the dentist performed a number of rotations of the torso, more pronounced on the right side. With regards to the use of the counter, there was a need to move the stool away, rotate to the right and get up, that is when the dentist does not remain seated and stretch to reach for some material on it. The great use of the large central drawer was observed, which despite having casters remained motionless under the counter (Figure 1). Another action, which drew attention, was the shift to the suction unit in order to turn it on and off. Most of these shifts were performed by gliding on the stool in the 3 o'clock position. Another was to 
physically get up from the stool and go to the unit to turn it on and off. The professional justified the procedure by it being a way to avoid overheating the compressor. Finally, it was observed that there were many times where the spotlight needed to be moved to avoid the patient bumping their head on it when sitting up to use the spittoon and when bringing forth the spotlight to focus light onto the equipment in order to improve visibility of an area which needed sculpting. During the observation, it was verified that the patient chair was not inclined enough in order to allow the dentist to pass behind it to access the suction unit, which suggests yet another reason not to use the Threndelemburg position with the patient.

\subsection{Pre-diagnosis}

From these observations the following prediagnosis can be formulated (Table 1):

This pre-diagnosis offers an explanation for the problem initially raised in the demand. From this point on, an observation plan was defined to perform the systematic observation of the activity.

\subsection{Systematic Observation}

Systematic observations were made based on the

Table 1

Pre-diagnosis

\begin{tabular}{|c|c|c|c|}
\hline Due to: & The dentist does the following: & This characterizes: & And frequently causes the dentist to: \\
\hline $\begin{array}{l}\text { the layout of materials } \\
\text { in the drawers and } \\
\text { cabinets; } \\
\text { the on/off switch of the }\end{array}$ & $\begin{array}{l}\text { uses the equipment and the counter } \\
\text { greatly to handle the materials; } \\
\text { highly uses the drawer unit to look } \\
\text { for/take the necessary material; }\end{array}$ & $\begin{array}{l}\text { A session without } \\
\text { prior selection of } \\
\text { materials. }\end{array}$ & $\begin{array}{l}\text { - perform various inclinations and rotations of the } \\
\text { torso as well as perform movements with the stool } \\
\text { which provoke physical fatigue and lumbosacral } \\
\text { pain with a loss of time in finding the desired } \\
\text { material; }\end{array}$ \\
\hline $\begin{array}{l}\text { adjustments of the } \\
\text { spotlight }\end{array}$ & $\begin{array}{l}\text { performs various movements with the } \\
\text { stool to turn to the suction unit; }\end{array}$ & & - avoid overheating of the compressor \\
\hline $\begin{array}{l}\text { the small space available } \\
\text { behind the headrest of the } \\
\text { patient's chair }\end{array}$ & $\begin{array}{l}\text { - insufficiently reclines patient's chair; } \\
\text { makes several changes of position of the } \\
\text { spotlight when the patient sits up to use the } \\
\text { spittoon and when there is a need to cast } \\
\text { light on the equipment. }\end{array}$ & & $\begin{array}{l}\text { - guarantee the safety, comfort and success of the } \\
\text { treatment }\end{array}$ \\
\hline
\end{tabular}

spine, more pronounced in the cervical region; a lack of support for the lumbar spine; inclination of the head to the right with left rotation; insufficient pre-diagnosis. An observation plan was drafted which resulted in a second cut in the activity: timing of the actions. The actions were categorized as intraoral and extraoral and occur $52 \%$ and $48 \%$ of the time, respectively. The approximate value was found in the literature for intraoral actions [9]. In this study, although the time difference is small, it becomes significant when one considers that the actions outside the mouth (48\%) have a direct relationship with the organization of work, while intraoral actions $(52 \%)$ are directly related to static postures, i.e., those that promote increased manual and visual accuracy of the tooth, but is also one of the factors responsible for the development of MSDs [22] as well as early retirement from dentistry $[3,15]$

During the systematic observations, it was possible to identify the restrictive elements and the strategies adopted to avoid them.

\subsection{Restrictive elements and strategies}

\subsubsection{Postures} positions far from the central axis. This is more important for intraoral intervention where tension and duration are aggravating factors.

Identification of the standard positions adopted by the dentist during intraoral action are: flexion of the
The nature of the dentist requires them to adapt support for the feet characterized by an extension greater than $120^{\circ}$ of the left knee and flexions lower than $90^{\circ}$ of the right knee. These positions were also 
identified in other studies $[1,22]$.

\subsubsection{ISO/FDI Standard}

Looking at Figure 1 again, there is a view of a graphic scheme superimposed on a dentist's office in accordance with ISO/FDI.

- Circle A: In this area the dentist, the assistant as well as all the material, instrumental and terminal equipment in use must be present, as this area is considered to be the ideal place to begin. In this case, one can see that the placements of the equipment as well as materials in the drawers, which appear open and contain the materials in use, are out of this space. This provision causes the dentist to perform many torso rotations to the right to grab the points of the equipment as well as material in the drawers.

- Circle B: Within this area there is the maximum space for handling. It must house the equipment, the rolling cabinet and the suction unit. The drawers of the cabinets when open should fall within this circle. In the case of housing the equipment, it is partially within the area indicated as being correct. On the other hand the suction unit with its on/off device and the hose are in agreement, however, for a fourhanded job, not a two-handed one.

- Circle C:There should be a sink and fixed cabinets in this area. It appears that these items are practically within the area cited.

\subsubsection{Two-handed work system}

The dental work is performed by using two hands, and this choice causes the dentist to adopt an intermediate working position, 10 o'clock or 11 o'clock according to ISO/FDI (Figure 1), where there is a need to be close to the patient, materials, the on/off switch for the suction unit and hold the hose of the said in the patient's mouth. This causes the dentist to continue the session with a greater degree of tension than if they had an assistant, which favors only in the dental procedure. She reports that when she had an assistant she had a better quality of life. The fourhanded job is usually more productive, reduces stress, and improves the efficiency along with the profits $[5,8]$

\subsubsection{The Equipment}

- Dental stool: During the observations it was found that the dentist was carrying out a great effort in order to move the stool due to the poor conditions of the casters. Changing them brought on a change in the way of working, making the professional more flexible and agile and performing movements much more effortlessly. The change also had an effect on coccyx pain, which subsequently disappeared. As for the measurements of the same in relation to the seat height, which is a little above the ideal, because the dentist has $38 \mathrm{~cm}$ (approximately 15 inches) of ground clearance to the popliteal fossa and the seat has $46 \mathrm{~cm}$ (approximately 18 inches). This height difference leads to a compression of the posterior thigh, which impairs blood circulation in this region is the extension of the left knee of up to $130^{\circ}$.

- Dental chair: The inclination of the chair allows the patient to be placed almost entirely in the supine position because its backrest varies from $110^{\circ}$ to $170^{\circ}$

- Drawer unit: The dentist uses the drawers in every session performed, but does not use the top of it and moves it even less even though it is mobile. All of the drawers are used to store material and instruments and during a session they are opened and closed many times in order to find an item which is needed. During an observation of a photo polymerization restoration session, the occurrence of this event was counted 27 times. The drawers in relation to the horizontal plan are within the maximum tolerance limits, in other words, $15 \mathrm{~cm}$ (approximately 6 inches) above elbow height [10].

- Equipment: The tray area used to handle the material and as support is $76 \mathrm{~cm}$ (approximately 30 inches) in height and the area to pick up the instruments is $66 \mathrm{~cm}$ (approximately 26 inches) tall. Considering the horizontal work layout between $68 \mathrm{~cm}$ and 83 $\mathrm{cm}$ (approximately 27 inches and 33 inches), it appears that the only the area where the instruments are picked up is a little below the ideal. However, the position is not the same as the one in accordance with ISO/FDI.

- Suction unit: The suction unit is an integral part of the auxiliary unit, so it is located to the left of the patient and attached to the spittoon, located where a right-handed dental assistant 
would be located. In the case studied, the suction unit is also left of the patient even though the dentist does not have an assistant. Another aggravating factor is that the switch as well as being located on the spittoon, has an on/off dial which causes her to always use her left hand making pronosupination movements. It is important to remember that she, the dentist, has left Lateral Epicondylitis. So, besides the professional having to move to the suction unit to get to the hose, she must also go to it in order to reposition it, and turn it off and on. This involves unnecessary movements, loss of time and compromises the left arm, because the dentist abducts and flexes the shoulder to reach the device and performs internal and external rotations of the entire upper extremity.

The following strategies were identified and adopted to reduce the constraints and restraints present in the job (Table 2).

\subsection{Diagnosis}

After having gone through the AET methodological path, it was possible to prepare the following diagnosis for the case:

Regardless of treatment, static postures are present

during the intraoral intervention, since they allow for focusing on the point that is being treated and it supports the increase of manual precision. This fact,

Table 2

Constraints and strategies adopted.

\begin{tabular}{|c|c|}
\hline Constraints & Strategies \\
\hline Fear of pain & $\begin{array}{l}\text { In order to have control over the fear of pain, the dentist has to be confident and respect the patient's } \\
\text { threshold of pain during a procedure. Earning the trust of a patient starts when the dentist makes } \\
\text { appointment him/herself, goes through a 1-hour session, which is aimed to be an initial consultation, } \\
\text { and ends with the completion of the treatment itself, which the professional seeks to promote a relaxed } \\
\text { environment through conversation and relaxing music. In addition to pain, it is initially established by a } \\
\text { signal (raise left hand) for the patient to signal when there is the slightest pain or discomfort. The } \\
\text { patient knows that the dentist is alert and will interrupt the procedure when the patient gives the signal. } \\
\text { A little carelessness can evoke the patient's defense mechanism and compromise the professional's } \\
\text { confidence. Health professionals are among those whom are expected to have a positive attitude while } \\
\text { interacting with patients, so they need to develop the emotional aspect of their work [6,17]. }\end{array}$ \\
\hline
\end{tabular}

Manual accuracy

Perfectionism in the work

Time management

Suction unit location

Restricted operating field

Since the intraoral intervention requires manual accuracy, the dentist adopts positions. To promote their own relaxation during and between sessions, the dentist should reserve one hour for each patient, put on relaxing ambiance music and walk between sessions to move around.

To ensure the quality of care from the first contact to the completion of the treatment, the dentist makes it a point to schedule the patients, a function which could be delegated to a secretary without compromising or interrupting a session.

The period of one hour for each patient eases the tension, because the time it takes to perform the procedure can vary according to the treatment and the difficulties encountered during the session and also compromises the schedule, which unsettles the professional. The professional knows they could perform a greater number of treatments per day, but states that the personal cost is too high and would rather wait than be waited for.

The equipment is designed to work four-handedly with a right-handed dentist. The suction unit is located to the left of the patient, where a dental assistant should be. In this case in order to turn it on, the dentist positions him/herself at 10 o'clock where they can intervene in the mouth, use the instruments and the suction unit.

To act with manual accuracy on the veneer of a tooth requires a good view of the location. For this the dentist uses the adapted magnifying glass suitable for dentistry and that gives direct view, which means there is a preference for manual accuracy. The use of a magnifying glass improves visual acuity, but does not address the musculoskeletal problems among these professionals [21].

along with the absence of an assistant, causes the dentist to position herself at 10 o'clock so that they can be close to the suction unit, hold and maintain the hose in the patient's mouth. In this position the professional needs to flex and abduct the left shoulder in order to position the upper limb over the patient's head, then incline the torso and head laterally to the right as well as rotate the latter to the 
left for a direct view of the tooth's veneer. Linked to this fact is the small amount of space available behind the headrest of the dental chair when in the supine position, i.e., $57 \mathrm{~cm}$ (approximately 22 inches), which leads to the use of a smaller inclination of the chair to be able to pass behind it with the stool to access the suction unit. This is even found when the patient has no physical restriction (labyrinthitis, pregnancy, senility, etc.), because the analysis proves that physical space is a strong restriction that interferes with the operative mode. Associated with these factors is the organization of the work that leads the professional to conduct numerous unnecessary movements and shifts to search for the desired material in cabinets and drawers, causing physical fatigue. The dentist excessively uses the counter due to its organization. To develop a peaceful and satisfying job, the welfare of the patient is an important factor. To achieve this, the professional dedicates the entire session to evaluate new patients, clarifying a case, consulting, receiving payments and payment schedules, and establishing the number of sessions required. This first contact decreases the expectation of the patient and prepares him/her for the next session in which the dentist uses resources such as quiet background music for relaxation.

\section{Conclusions}

The AET was found to be a very suitable method to study and comprehend the activity.

It was possible to build a point of view of the profession by learning about the determinants of this activity, constraints and strategies adopted by the dentist to mitigate them. It is characterized as stressful, requiring a control of the fear of pain, not only from the patient but also fear of the dentist in which the dentist fears it becoming apparent to the patient. The dentist is also of a perfectionist nature, and the pursuit of success in treatments and patient satisfaction represents more than one workload. The wear and tear from the pursuit of perfection, from scheduling to maintenance of clientele further contributes to the increase of tension existing in static postures. Finally, as an activity restricted to intervention in a small area, the need for manual and visual precision, for the adapted static postures, and for the economic issue that deprives the professional from having intraoral and extraoral assistants.

\section{References}

1. D.J. Ahearn, M.J. Sanders, C. Turcotte, Ergonomic design for dental offices, Work, 5(2010), 495-503.

2. I. Akesson, I. Balogh, S. Skerfving, Self-reported and measured time of vibration exposure at ultrasonic scaling in dental hygienists, Applied Ergonomics, 32(2001), 47-51.

3. E.C. Alexopoulos, I.C. Stathi, F. Charizani, Prevalence 1. of musculoskeletal disorders in dentists, BMC Musculoskeletal Disorders, 9(2004), 5-16.

4. F.J. Burke, J.R. Main, R. Freeman, The practice of dentistry: an assessment of reasons for premature retirement, The British Dental Journal. 182(1997), 250-254.

5. B.L. Finkbeiner. Four-handed dentistry revisited, The Journal of Comtemporary Dental Practice, 1(2000).

6. A.A. Grandey, Emotion Regulation in the Workplace: A New Way to conceptualize emotional labor, Journal of Occupational Health psychology, 5(2000) 95-110.

7. F. Guérin, A. Laville, F. Daniellou, J. Duraffourg, A. Kerguelen, Compreender o trabalho para transformá-lo: a prática da ergonomia, Edgard Blücher, São Paulo, 2001.

8. D.C. Holmes, L.J. Squire, S.K. Arneson, J.V. Doering, Comparison of Student Productivity in Four-Handed Clinic and Regular Unassisted Clinic, Journal Dental Education, 73(2009), 1083-1089.

9. D. Jonker, B. Rolander, I. Balogh, Relation between perceived and measured workload obtained by long-term inclinometry among dentists, Applied Ergonomics, 40(2009), 309-315.

10. K.H.E Kroemer, E. Grandjean, Manual de Ergonomia: adaptando o trabalho ao homem. Bookman, Porto Alegre, 1998, 338p.

11. P.A. Leggat, U. Kedjarune, D.R. Smith, Occupational Health Problems in Modern Dentistry: A Review, Industrial Health, 45(2007) 611-621

12. J. Mangharam, J. McGlothan, Ergonomics and dentistry: a literature review, in: D.C. Murphy, Ergonomics and the Dental Worker, American Public Health Association, Washington, 1998, pp. 25-82.

13. W. S. Marras, K.G. Davis, C. A. Heaney, A. B. Maronitis, W.G. Allread, The Influence of Psychosocial Stress, Gender, and Personality on Mechanical Loading of the Lumbar Spine, Spine, 25(2000), pp 3045-3054.

14. E.D. Marshall, L.M. Duncombe, R.Q. Robinson, S.L. Kilbreath, Musculoskeletal symptoms in New South Wales dentists, Australian Dental Journal, 42(1997), 240-246.

15. E. Milerad, M.O. Ericson, R. Nisell, A. Kilbom, An electromyographic study of dental work, Ergonomics, 34(1991), 953-962.

16. L.M. Rucker, S. Sunell, Ergonomic risk factors associated with clinical dentistry, Journal of California Dental Association, 30(2002) 139-148.

17. J. Schaubroeck, J.R. Jones, Antecedents of workplace emotional labor dimensions and moderators of their effects on physical symptoms, Journal of Organizational Behavior, Journal Organizational. Behavior, 21(2000), 163-183.

18. B.P. Shrestha, G.K. Singh, S.R. Niraula, Work related complaints among dentists, Journal Nepal Medical Association, 47(2008), 77-81.

19. D.A. Shugars, M.R. DiMatteo, R.D. Hays, S. Cretin, J.D. Johnson, Professional satisfaction among California general dentists, Journal Dental Education, 54(1990), 661-669.

20. C.A. Smith, C.M. Sommerich, G.A. Mirka, M.C. George, An investigation of ergonomic interventions in dental hygiene work, Applied Ergonomics, 33(2002), 175-184. 
21. S. Sunell, L. Rucker, Surgical magnification in dental hygiene practice, International Journal of Dental Hygiene, 2(2004), 26-35.

22. B. Valachi, K. Valachi, Mechanisms leading to musculoskeletal disorders in dentistry, Journal American Dental Association, 134(2003), 1344-1350. 